\title{
Development of strategic asset management planning in the petroleum industry
}

\begin{abstract}
Purpose - Due to the certain risk carried in offshore petroleum installations, the integrity of these installations needs to be maintained at all times. Thus, asset integrity management (AIM) needs to be formulated and monitored to achieve the integrity objective. This paper studies the practices and progression of strategic AIM planning in the petroleum industry.
\end{abstract}

Design/methodology/approach - The paper is written based on a literature study, observations, and data collected from industry practitioners through an online questionnaire and interviews to study the AIM practices in their organization. Validation of the results is performed through respondents' reviews and cross-referencing with existing literature and supplemental data.

Findings - The paper identifies, analyses and validates the work structure in formulating an AIM strategic plan.

Research limitations/implications - Even though the research focuses on the AIM practices of offshore petroleum installations, the result can be implemented in similar fields.

Originality/value - Researchers or practitioners can benefit from the knowledge gained of current practices and the presented work structure in establishing an AIM strategic plan.

Keywords - Asset integrity management, Asset management, Petroleum, Oil and gas, Strategy, Strategic planning, Lifecycle approach.

Paper type - Research paper

\section{Introduction and background}

Asset integrity management (AIM) is an adaptation of asset management (AM), especially in the petroleum industry, due to the definite risk it bears that requires integrity to be maintained over the entire lifecycle. As part of the management of physical assets, AIM has brought a holistic approach in managing the lifecycle of a physical asset (Ritchie, 2011). In this industry, AIM activities have expanded from the pre-operation phase through to the decommissioning phase. In addition, AIM activities, such as maintenance and inspection, have also shifted from playing a tactical role to playing a strategic role (Sollee et al., 1995; Tsang, 1998).

A study by Pinjala et al. (2006) found that organizations that competing on quality (i.e. qualitycompetitors) have better planning process and control systems when compared to others. This means that an organization can be directed towards reaching a certain competitive advantage. The study also found that there is a relationship between business strategy and maintenance strategies, where the maintenance strategy seem to be in line with their business and objectives of the company (Pinjala et al. (2006). However, unlike maintenance strategy, AIM strategy covers a 
larger area across business and technical disciplines in the internal and external organization, which increases its vulnerability (Janele et al., 1998).

Moreover, often AIM strategies fail due to the lack of both integration and unified effort from different groups in the organization (Ciaraldi, 2012; Parida et al., 2015). Thus, different groups in the organization need to be led towards the same goal, and to align different groups the organization needs to develop a strategy and a plan to implement it (Steiner, 1979). For this to happen, there is a need for AIM strategic planning, where AIM activities are directed to achieve the organizational strategy (El-Akruti and Dwight, 2013; Woodhouse, 2003).

The notion of strategic planning has been around since the 1960s and has been discussed, implemented and improved in so many ways (see for example Mintzberg, 1994; Killen et al., 2005; Haines, 2000). However, there is a lack of strategic planning models designated for AIM in the petroleum industry and that have received feedback from industry practitioners (see for example Al-Turki, 2011; Capon et al., 1987; Grant, 2003). Additionally, there is a limited amount of literature on strategic planning within the petroleum organizations, and most analyses were not based upon the notion of strategic planning processes (Grant, 2003).

To fill this gap, this study focuses the practices and progression of AIM strategic planning. The paper will be taking an example from the petroleum industry due to the importance of AIM in this industry, particularly for offshore installations. Data collection will involve a questionnaire, interviews with industry practitioners, and supplemental sources provided by respondents to support the interview data. The analysis will be instigated by finding the key variables in the organizations' AIM strategic planning practices and then linking them to the characteristics of the respondents' organizations.

\section{AIM strategic planning in the petroleum industry}

The management of asset integrity is gained through integrated access and control over the installation in order to achieve the desired integrity (Bai and Liyanage, 2012; Sulaiman and Husin, 2000). In the petroleum industry, the desired integrity level is the capability of an installation to perform its required function in a prescribed manner.

\section{Asset integrity management (AIM)}

Asset integrity management is a part of asset management. The term 'asset' in this study refers to the physical asset, and the term 'integrity' takes the meaning of technical integrity. Within the petroleum industry, the technical integrity of an asset is normally associated with the ability of the asset to perform its required function in a safe, effective and efficient manner, particularly with the ability to safely contain or process hydrocarbons and other related substances according to the defined function and stated requirements (Jansen and Firing, 2016). A petroleum asset will degrade, and it can only perform its required function if preserved properly over its life. To be able to sustain the desired integrity level, an organization needs to balance the asset's capabilities against the AIM constraints, safety, risks, and the associated budget over its life cycle as illustrated in Figure 1. In Figure 1, the term 'capability' of an asset refers to the ability and 
potential of an asset to achieve its intended functional performance, production performance and availability performance (Markeset, 2010) in a safe, timely and high quality manner. The elements related to 'risk' in this context cover all the possible consequences (outcomes) of an event, including hazard, threat or opportunity (ISO 55000:2014). The elements related to 'resources' are the organization's commitment to spending what is required for the installation's expenditures, including various resources. The elements related to 'constraints', however, are parallel to various inherited challenges faced by the offshore installation, such as production challenges, technical challenges, degradation, weather, geographical conditions, etc. (Kusumawardhani \& Ratnayake, 2011, Javaherdashti et al., 2016). These main areas must be balanced out optimally and sustainably in order to reach the desired integrity level and maximize return on investment, as shown in Figure 1.

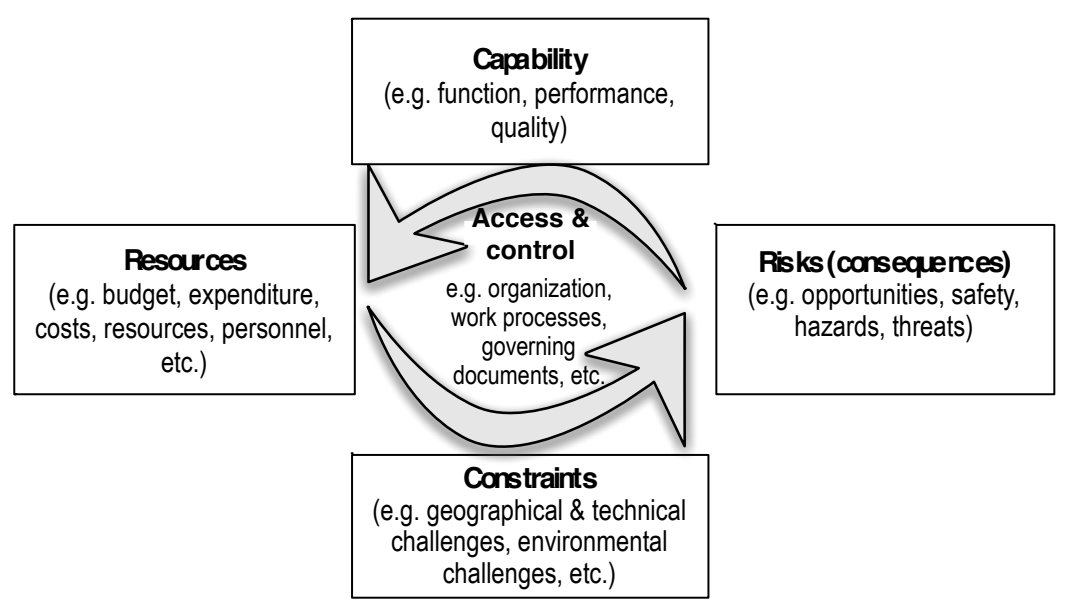

Figure 1. Balancing the AIM areas of an offshore production installation

Thus, in this study, AIM will be defined as: "the development, execution and evaluation of a coordinated plan together with managerial control and organizational activities, to ensure that the physical asset is carrying out its intended performances in a safe, effective and efficient manner over its entire lifecycle, in order to achieve the organizational objectives". (Kusumawardhani et al., 2016)

\section{Strategic planning (SP)}

Planning is not new in the petroleum industry, and the term 'planning' has a clear and definite meaning as the process or activity of making plans. However, the terms 'strategic' and 'strategic planning' (SP) seem to be vague and are understood differently by scholars and practitioners (Nag et al., 2007; Carr and Smeltzer, 1997). The term 'strategic' is often related to the organizational interest or important matters, which would affect the well-being of the organization, and SP is related to the planning of that important matter (Steiner, 1979).

Different scholars have also suggested that SP is part of the long-term corporate planning, but, regardless of the different views on SP, most of the definitions describe SP as an organizational process that attempts to anticipate future decision-making by forecasting the probability of 
consequences that arise from current action and knowledge (Capon et al., 1987; Miller and Cardinal, 1994; Al-Turki, 2011). The result is formulated in strategies and planning that will drive and allocate the organization's resources to achieve the organization's objectives.

Another characteristic of SP is that it is a form of a continuous systematic process that begins by defining organizational aims and establishing strategies to achieve them (Steiner, 1979). The process is continuous in order to be able to adapt to the changes in the internal and external environment, especially with the fluctuating fossil fuel price and the rapidly changing technology in the petroleum industry (Kusumawardhani and Markeset, 2015).

From the discussion, it is foreseeable that SP is the way for an organization to deal with uncertainties. Additionally, SP is essentially a process of identifying opportunities and threats that are significant to the organization's objectives. The SP process facilitates organizations to perform decision-making processes to secure their competitive advantage in the future. The act of planning is performed to direct their resources' allocation and anticipate the future situation.

A similar process was defined by Aven (2008) as risk (C, C*, U, P, K), as shown in Figure 2. According to this definition, risk is the consequences $(C)$ of the activity (including the initiating event $\mathrm{A}$ ), which is affected by uncertainties (U) that are associated with whether or not A will occur and which values $\mathrm{C}$ will take. $\mathrm{C}^{*}$ is the prediction of $\mathrm{C}$, and $\mathrm{P}$ is the probabilities of how likely various events and outcomes are, and they are based on prior knowledge $(\mathrm{K})$.

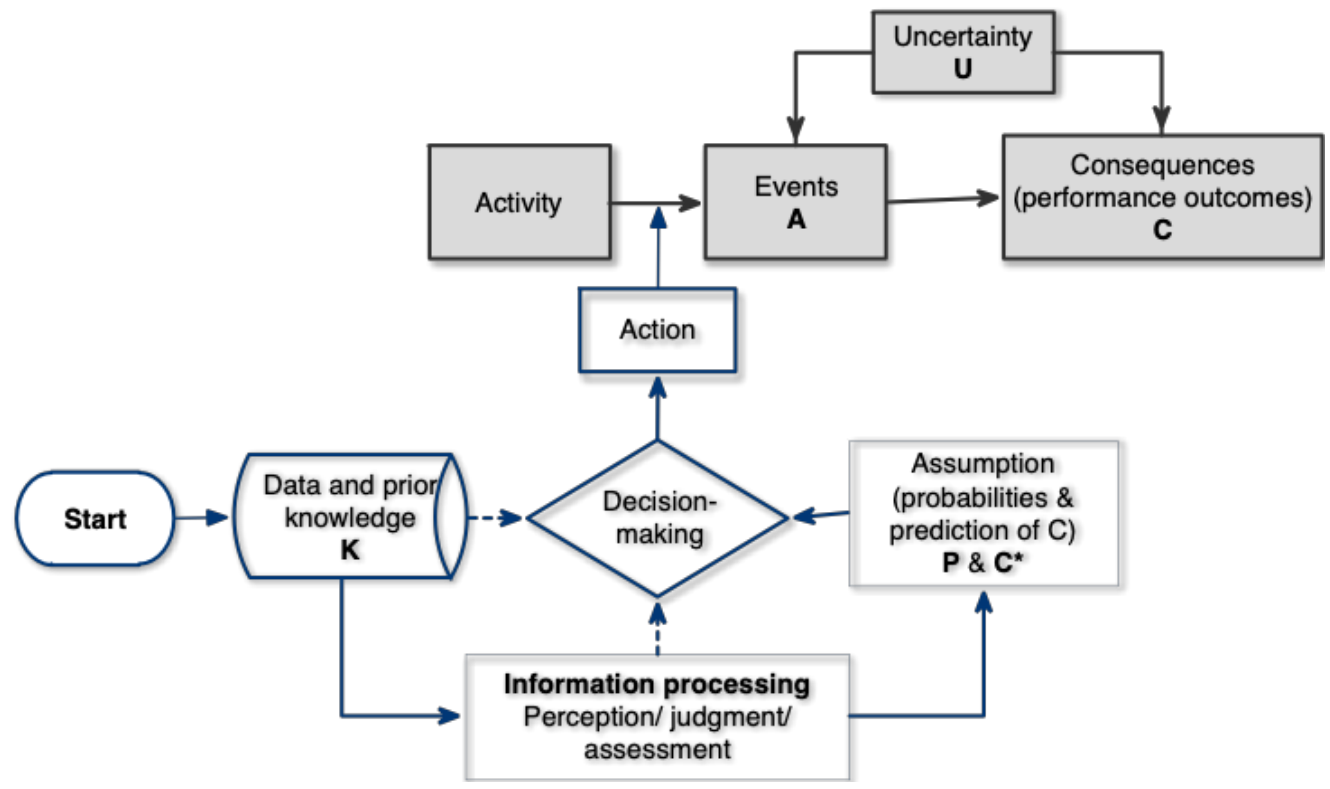

Figure 2. Decision making process based on risk description (C, C*, U, P, K) (Aven, 2008)

In this definition, risks are both opportunities and threats, including all possible consequences that might arise, which in AIM would include business and technical terms. This definition will delineate the term 'risks' throughout this paper. Related to this definition, the SP process is essentially a decision-making process to manage foreseeable risks, and it may be linked to strategic decision-making (Grant, 2003). Additionally, Capon et al. (1987) also emphasize the 
continuous process loop in SP to tackle the volatile business environment. Thus, for the purpose of this paper, strategic planning is defined as "a systematic and continuous process of risks identification that uses probabilities and other knowledge as a basis to forecast consequences to undertake anticipatory decision-making of resources allocations to achieve the organization's objectives" (Steiner, 1979; Capon et al., 1987; Aven, 2008).

\section{Recent development of strategic AIM planning}

Since the 1990s, the strategic planning practices in the petroleum industry have changed into a more informal and decentralized process to adapt to the turbulent and unpredictable business environments (Grant, 2003). This creates a semi-structured process, where the bottom-up decentralization allows more freedom for business units to formulate their own strategy, without loosing certain control from the organization (Brown and Eisenhardt, 1997). Larger organizations would normally establish a set of performance standards or key performance indicators (KPI) for their offshore units, but nowadays it is a more common practice for divisional business units, such as operation and maintenance, to have more influence on their department's strategy.

The volatile environment also formed a more responsive strategic decision-making, which creates a shorter term for strategic planning and is more focused on performance-management and goals. as well as more into performance-management and goal focused (Grant and Cibin, 1996). This term stretches the definition of strategic planning, which was previously viewed as long-term planning, into a process, which is more adaptive to the strategic decision-making. This change provides a strong background for a petroleum installation's quarterly appraisals and its business units, which are updating their plans yearly.

Mankins and Steele (2006) stressed that the differences between strategic decision-making and strategic planning, and claim that strategic planning is about documenting choices that have already been made rather than about making decisions. This is in accordance with Mintzberg (1994), who distinguished between deliberate strategy and emergent strategy. The first was based on original intention, and the latter consists of the organization's responses to a variety of unanticipated events. The delineation between the two brings forward the continuous improvement characteristic in the SP process, which enables incidental decision-making to be incorporated into the plan. Successful organizations have figured out a way to integrate these two processes, as observed by Brown and Eisenhardt (1997), such that the organization's consideration of the present and future (plans) gives a direction for change.

For asset integrity management of petroleum installations, long-term strategic planning is established at the design phase and reflected in the life cycle plan with a span of around 25-30 years, while the shorter-term strategic planning is normally reflected in five-year and yearly plans and monitored in a timely manner through performance measurement or performance management (Grant and Cibin, 1996; Tsang, 1998; Grant, 2003; Parida and Kumar, 2009). In accordance with bottom-up decentralization, divisional strategic planning is assigned to related business units, for example to the operations and maintenance department, which drives the development of strategic planning in this area (see for example Horner et al., 1997; Tsang, 1998; 
Murthy et al., 2002; Al-Turki, 2011). From thereon, the strategic planning evolves alongside the progression of operations and maintenance management into asset integrity management (Ratnayake, 2012).

The establishment of asset management was buoyed by the publication of PAS 55 in 2004 and the ISO 55000 series in 2014 (Standardization, 2014). AIM has been known in the petroleum industry as an integrated management of the petroleum installation to achieve the desired integrity. Besides method and research developments in AIM (for example Baby, 2008; Ratnayake, 2012; Bharadwaj et al., 2012), there have also been developments in software that are promoting 'integrated' access to strategic areas of AIM (Quinn et al., 2007; Kusumawardhani and Markeset, 2015). Therefore, since the focus has shifted to AIM, it will be beneficial to study the strategic planning process in this area.

\section{Study method}

Research was conducted to study the practices and progression of AIM strategic planning in organizations with petroleum installations. Respondents work in the petroleum industry and were given the same set of questions. The study utilizes a mixed method and consisted of two parts, a semi-structured guided interview and a questionnaire (Brannen, 2005), as illustrated in Figure 3. The semi-structured guided interview was mostly performed face-to-face whenever possible, while, in the second part, respondents were asked to fill in a questionnaire.

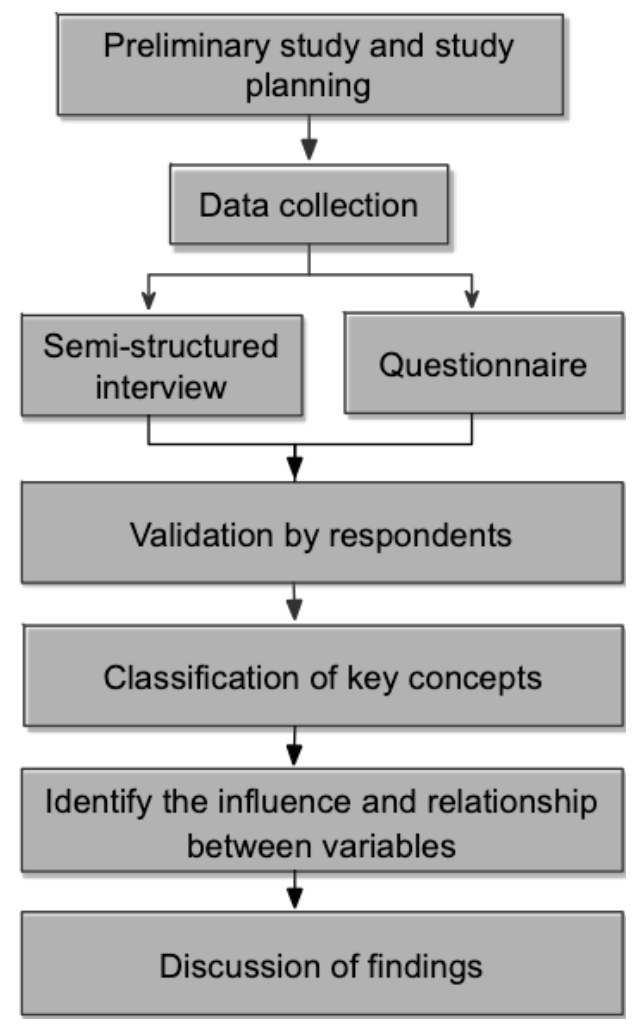

Figure 3. AIM strategic planning study method

The interview method was chosen primarily to observe the phenomenon from the respondent's point of view through a structured approach, while the questionnaire aimed to observe the trends 
amongst the respondents (Creswell, 2003). To maximize the reliability and validity of measurement and to attain a better understanding of the organization's strategy, all of the respondents held senior management positions. However, views from other non-management employees were also collected whenever possible and taken into consideration to represent both perspectives and triangulation of data. Triangulation of the result is also achieved by crossreference with the organization's procedures, processes and publicly available resources such as the organization's website.

Both methods were performed with the cooperation of six industry practitioners located in Norway and Houston, Texas, USA. Face-to-face interviews were conducted with the four respondents located in Stavanger and Oslo, Norway, and one respondent in Houston was contacted through emails. All of the respondents have 10-33 years of experience in the petroleum industry and all hold managerial positions in installation management and at a corporate level. To diversify the respondents' perspectives of the petroleum industry, respondents were taken from service users and service providers, with four respondents working for operator companies and the other two, for service companies. All respondents are working in multi-national organizations and their field of responsibilities are all related to asset integrity management, operations and maintenance of petroleum installations. Two (2) of the respondents are working for small to medium size organizations ( $\leq 250$ employees) and the others are working for a larger organizations ( $>250$ employees).

\section{Research questions \& analysis methods}

The questions were developed through thae literature study and from observations, as well as with the collaboration of senior researchers. The questionnaire addressed the background information of AIM strategic planning in the organizations, while the interviews aimed to study the practices of AIM and AIM strategic planning related to the petroleum installation, the performance management of the strategy and potential improvements around this area. Preliminary questions addressed the organization's practices in AIM in relation to the petroleum installations and then progressively moved towards the process of developing AIM strategy and how they measure the strategy performance. The respondents were also asked to evaluate a strategic planning process based on Haines (2000) model as shown in Figure 4. This model was chosen because of the general terms it uses and the detailed steps of the process. The figure was also modified to fit into this study topic. 


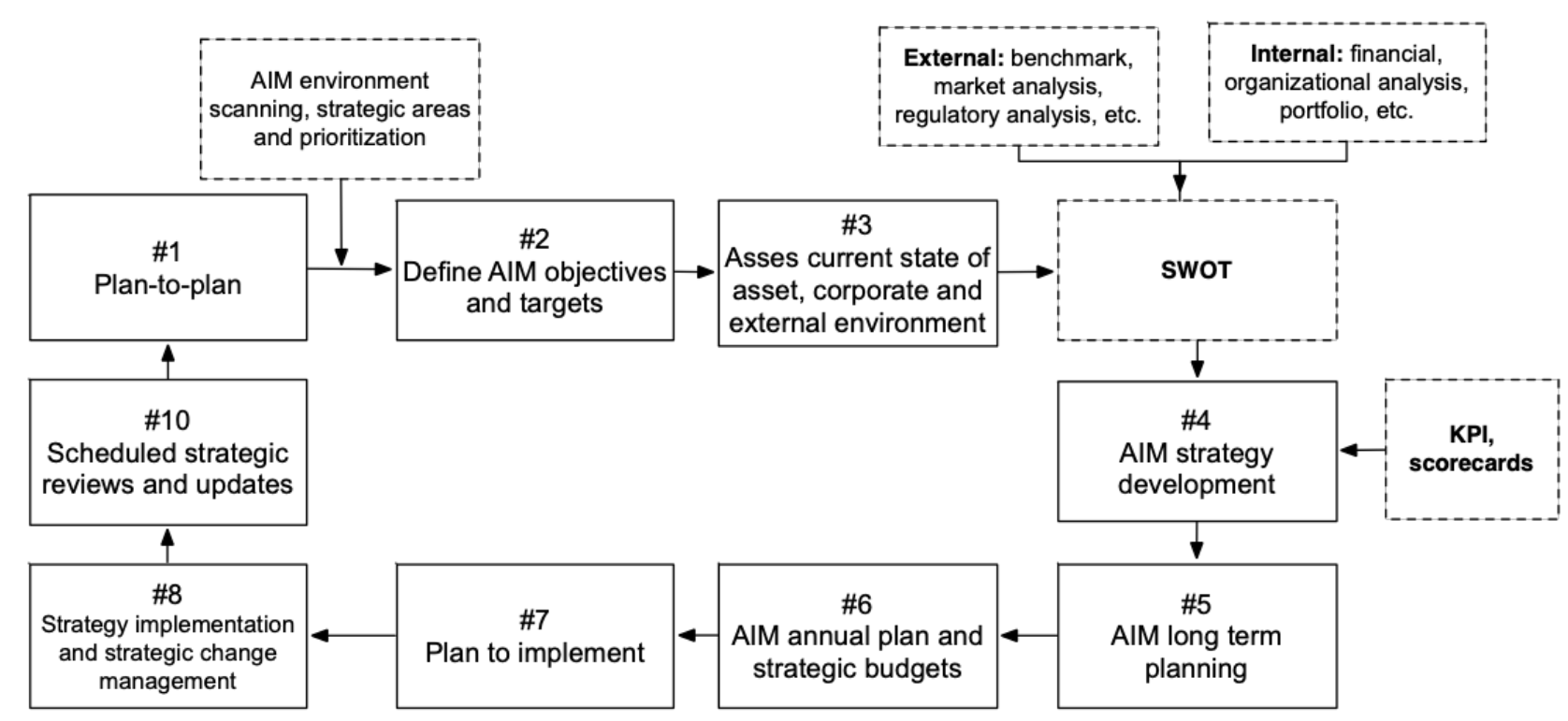

Figure 4. Initial AIM strategic planning model (adapted from Haines, 2000, p.50)

Most of the reference literature for developing questions in AIM practices and performance management comes from research papers in operation, and maintenance and performance management (for example Murthy et al., 2002; Tsang, 2002; Al-Turki, 2011; Parida et al., 2015), while questions related to AIM strategic planning were based on previous research in the petroleum industry (for example Casertano, 2013; Grant, 2003; Mitchell and Mitchell, 2014) and several classic works in strategic planning (for example Steiner, 1979; Hax and Majluf, 1984; Capon et al., 1987; Miller and Cardinal, 1994; Mintzberg, 1994; Haines, 2000).

The results from the questionnaire were analyzed for trend and some variables were ranked according to the responses. Notes taken during face-to-face semi-structured interviews were summarized immediately after each interview and sent back to the respondents for validation of content. Additionally, some of the respondents also provided access to company documents to support the interview data. The interview results and the supporting data from each organization were analyzed to distinguish some of the key variables that later on were collectively analyzed with the results from other organizations.

\section{Findings}

Although the interview questions are the same for all the respondents, the quantity of information received from the respondents varies from one to another, depending on the confidentiality level of the organizations in which the respondents work. The questionnaire provided preliminary data of the organization and several scalable parameters that are related to the interview questions. The questionnaire data were analyzed in conjunction with the data gathered from the interviews. The analysis showed that there were several key variables that can be related to the formulation of AIM strategic planning in the petroleum industry. 


\section{AIM strategic planning practices overview}

All of the respondents agreed that, ideally, an AIM strategy should be established early in the life cycle of a petroleum installation. The reasons are mainly attributed to sustainability, to implementing a strong foundation in AIM before operation and to the greater requirement of time and resources if AIM is established later in the installation's life cycle. The latter has become one of the main challenges for smaller organizations wishing to apply AIM strategic planning, as most of the smaller organizations have smaller fleets and less capital. The cost of establishing AIM early in a petroleum project is reported to range from USD 10 million up to USD 21 million on project sizes of USD 900 million to USD 1.45 billion (Smith et al., 2002); these figures could be higher when the work is performed after the asset has begun to operate.

For example, the respondents from smaller companies implement maintenance and operations management with accordance to class rules and regulatory compliance, depending on the country where the facility is operating. However, asset integrity is not very well defined and planned over the entire organizations. For example, the company might be based in Norway but they have fleets operating in the Asia or Africa regions where the regulatory regarding AIM is not as strict as in Norway. With this considerations, plus other factors such as remaining life, contract terms, etc., it might not be profitable to imply full AIM requirements in their aging facilities.

From the interviews, it was observed that companies see AIM strategic planning more as midterm planning (5-10 years), which can be adjusted yearly by tactical plans (one to two years). The application of yearly tactical plans is a form of continuous improvement in strategic planning. Additionally, one of the respondents expressed the importance of documenting all steps in the planning process for future reference.

From the questionnaire it was also found that the smaller size organizations have neither established formal AIM strategic planning nor put a similar process in place. The larger organizations have implemented more decentralized strategic planning processes since the 1990s, while the smaller organizations are planning to establish such formal processes in accordance with the growth of their organizational size. The respondents from smaller organizations see that AIM strategic planning is a form of organizational alignment and perceive that it is still not needed in an organization their size. These organizations perform AIM strategic planning at the beginning of an asset's life cycle with long-term duration between 20-30 years. This is not normally updated until the asset is modified, decommissioned or changes owners.

In larger-size organizations, the formal AIM strategic planning processes are performed every three to five years and more tactical planning, in a yearly or two-yearly cycle. Studies and analysis to produce forecasts or strategic business reviews would initiate the strategic planning cycle, followed by the issuance of a corporate strategic plan and guidelines from the corporate management and additional input from stakeholder requirements.

The mid-managerial divisions may adjust forecasting and guidelines accordingly to fit the business units' specialization. For example, in one of the respondent's organization, the corporate 
objective was to optimize overall efficiency in the organization; the divisional management then set a goal for a $25 \%$ increase in production efficiency and a further $25 \%$ in process and manpower efficiency. Then AIM planning will be drafted from the bottom up, starting from the business units.

The corporate guidelines would pertain to environment scanning and business forecasts, possible scenarios, general objectives and an outline for the strategy, while the stakeholder requirements might be related to client, government or class requirements. Moreover, there are additional requirements that are unique to the asset, discipline or geographical area, for example class requirements or the country's specific standards. Other factors that were considered as input for AIM strategy are previous performance reviews (e.g. asset, strategy, resources, financial), challenges and opportunities, technology and innovation, support services, HSSEQ (health, safety, environment, safety and quality) records, OPEX (operating expenditure) records, benchmarks, etc.

Since AIM involves multi-disciplinary subjects, there are several different disciplines that are integrated in the process, such as operation, maintenance, operation support, engineering, supply chain, etc. According to two of the respondents, in their organizations there will be a vocal point that coordinates the input between different disciplines and holds meetings between these disciplines.

Based on available guidelines, the business units responsible for AIM will then perform an internal strategic planning process to formulate a strategy and suggest KPIs (key performance indicators) for performance evaluation. The respondents from larger companies reported that the business units also conduct environment scanning or SWOT (strengths, weaknesses, opportunities and threats) analysis to address their focus area accordingly. One of the respondents believes that all related factors are important for asset integrity, but it is challenging to address them all at the same time due to time and budget restrictions. Thus the environment scanning would prioritize these factors and allocate resources to the most vital. The strategic planning drafts will be evaluated from the bottom up and revised accordingly to regulate OPEX and other budgets until the committee board approves it. This process is in illustrated in Figure 5.

Compared to previous top-down practices, the respondents consider that it is much more reasonable if the business units are given more freedom in deciding which strategy they will take. 


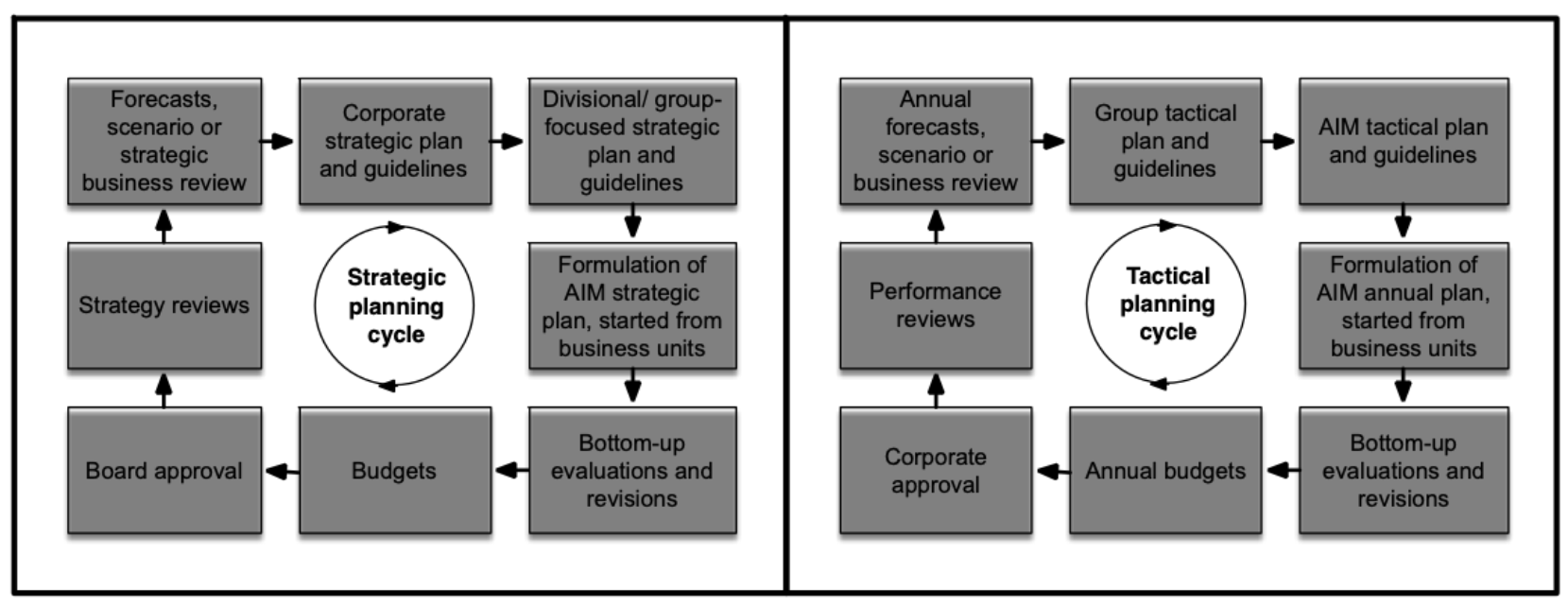

Figure 5. Typical AIM strategic and tactical planning cycle

\section{Content and performance management}

According to the respondents, the content of an AIM strategy outlines how the business units will uphold the asset's desired integrity level and how the asset will contribute to the organizational objectives. The AIM strategic planning would be an integration of inputs from several related disciplines and clearly outline how to implement, monitor and review the strategies related to the AIM activities, for example, maintenance strategy and replacement strategy for different equipment types, production strategy related to topside and reservoir, manpower and training strategies, etc. Compared to implementation planning, AIM strategic planning would give a more general direction and fewer details on activities.

The practices in the respondents' organizations are vary, depending on their organizational structure. On the smaller organization, this practice can be as simple as assigning a coordinator that responsible for asset integrity management for their facilities. Others with more complex organizational structures are appointing coordinators from each department to ensure the input and implementation into the integration process.

When submitting the draft for the strategy, business units also suggest a set of KPIs, which the corporate management will review and revise accordingly. The corporate management has normally set a performance indicator related to the organizational objectives; the final performance indicators would be agreed between corporate management and business units. Generally the respondents stated that the focus of the performance review would mainly cover financial performance (OPEX), HSSEQ (health, safety security and environment) performance, technical asset performance (e.g. integrity, production, downtime, maintenance backlog, etc.) and human performance. The specific targets and indicators are determined and agreed beforehand.

Most of the respondents agree that AIM strategic planning needs to be periodically reviewed to adapt to the changing environment in the petroleum industry. With the fluctuating oil price, organizations need to be more adaptable and more responsive to changes. In yearly planning, one of the respondents claimed that the asset's performance is reviewed quarterly with an automated AIM system, while others range from every six months to a year. 
A quarterly review, according to one of the respondents, allows the business units to make strategic decisions in response to current situations. Two other respondents argued that a quarterly review requires more resources and time. The other respondent for smaller organizations also reasoned that to employ AIM software for a quarterly review would be ineffective spending compared to the size of the organization. Instead, the smaller organizations outsource the performance measurement activities through a third party, such as through class inspections or other service providers. It was noted, however, that these smaller companies were outsourcing their AIM activities but not their AIM core competences. For example, one of the companies outsource their inspection activities and the analysis of findings to a service company without giving authority for decision-making outside of their scope. The company entrust this working process and the decision-making function to the internal supervisor or engineer.

\section{Environment scanning, risk management and the strategic areas}

Four of the respondents agreed that any planning process should begin with an assessment of the asset's business environments, which consist of the organization's internal and external environments. This part of the process is generally known as environment scanning, although the respondents' organizations use different terms and techniques such as strategic analysis, SWOT, benchmarking, portfolio analysis, etc.

From the environment scanning, organizations would try to estimate future consequences and determine which area to focus on in the planning. These areas of focus are also called strategic areas or strategic dimensions (Tsang, 2002). According to one of the respondents, strategic areas could vary from one term to another. It would depend on the result of environment scanning and the guidelines from corporate management. According to one of the respondents, almost every factor is significant for AIM; however, issues need to be prioritized and addressed accordingly. In addition, scenario planning is also presented in two of the respondents' organizations, which they think is especially useful in the fluctuating situation of the petroleum industry.

In the interviews, four of the respondents stated that, due to the certain risks they carry, AIM planning for petroleum assets involves prioritizing risk management and also performance management. The ISO standard 55002:2014 also prescribes a risk-management approach for planning physical asset management, alongside other organizational objectives. Additionally, one of the respondents claimed that nowadays it is common for the new-built assets to adopt a life cycle approach for their AIM planning. Life cycle analysis would provide further coverage in the integrity planning of the facility, extending beyond the organization's responsibility period.

In the operations phase, a continuous AIM effort needs to be sustained at all times. The result was apparent, since one of the respondents declared that, even after the life extension assessment, most of their facilities do not require extensive modifications; this is due to the continuous effort expended in maintaining the facility's integrity. This approach will be useful in cases beyond the expected responsibility period such as life extension, conversion, and trade or decommissioning. 
One of the respondents also gave the reason that strategic planning is basically the organization's attempt to optimize their competitive advantages against possible threats, by forecasting and managing their potentials and weaknesses. This concept is similar to Figure 1 on balancing the different AIM areas. The respondent also added that, in addition to forecasts, petroleum assets are also being prepared against unforeseen circumstances through emergency preparedness planning. The unforeseen circumstances could be accidents, incidents, security threats, hijacking, severe weather, fire and explosion, etc.

\section{The planning structure}

Since most of the respondents' organizations chose to withhold their strategy planning documents, the interviews took place so that the respondents could explain the process verbally and compare their practices against an AIM strategic planning structure presented in Figure 4. From their responses, all of the respondents agree that the model is applicable and that their organizations have similar processes in practice. The smaller organizations, however, are limited in terms of the allocation of resources and budget, thus seeing AIM strategic planning as mid-term or long-term planning. Instead, they adjusted their budgeting (OPEX) every one to two years and their tactical objectives when necessary.

The biggest change that was suggested to Figure 4 was to clearly distinguish between the corporation's and the business unit's processes. Corporate also tend to have static objectives (static targets) in their guidelines, thus the business unit need to further specify their objectives and performance indicators. Another suggestion is to change the term 'annual plan' into 'tactical plan', since the period could vary for different organizations. These changes were incorporated into a new structure, as shown in Figure 6.

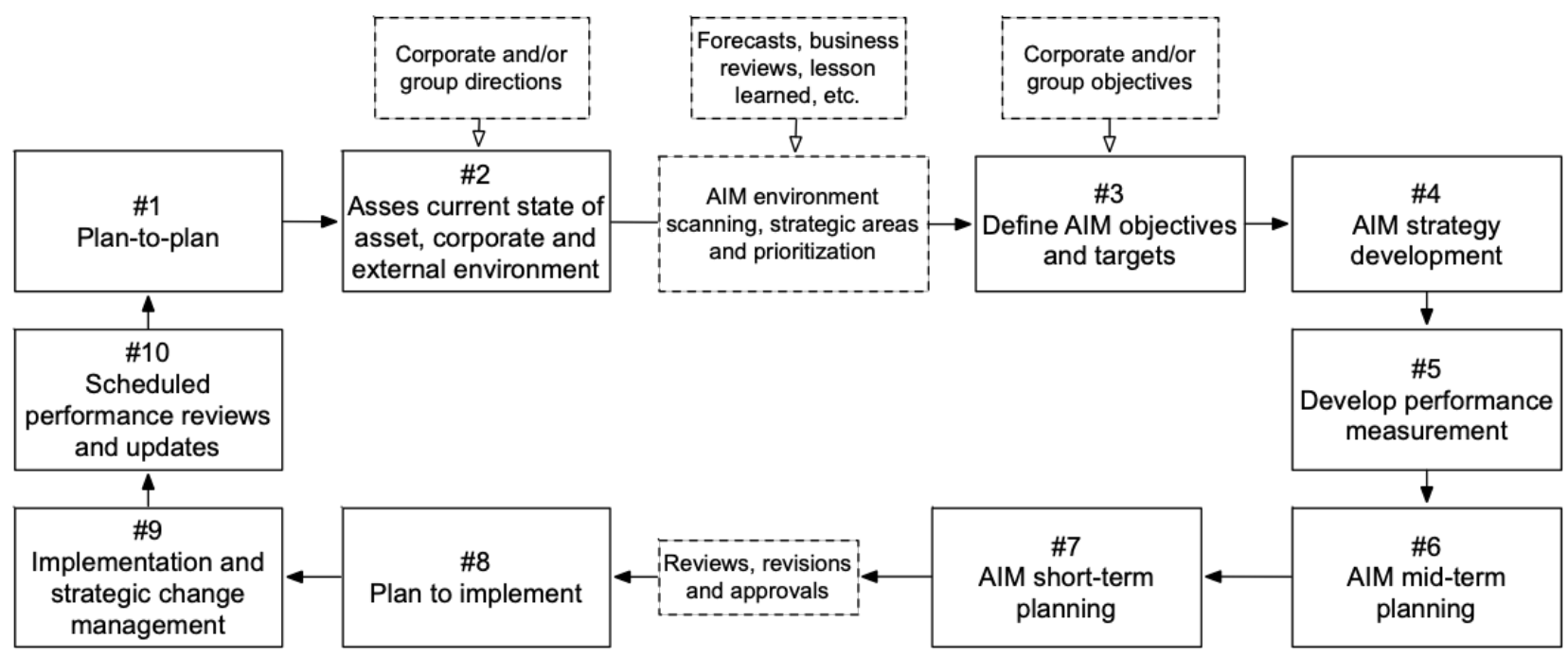

Figure 6. Revised AIM strategic planning model

Although it may be known by different terms in other organizations, 'environment scanning' is still a fundamental step in initiating the AIM planning process. Moreover, AIM possesses unique potential and traits due to the multi-discipline nature and its position between corporate business 
and direct connection to the asset. Prioritization is also a part of environment scanning, which gives significance to the more imperative subjects for resource allocation.

It was also noted that the larger organizations were restructuring their AIM processes; this was one of their recent strategic planning objectives. Efficiency is especially promoted in the corporate strategic plan. This was mainly due to the fluctuating oil price since 2014 . One of the respondents claims that they have recorded a significant increase of $90 \%$ in production efficiency in one of their LNG (liquefied natural gas) facilities. Despite the fluctuating oil price, all of the respondents agreed that the integrity of the asset would not be compromised.

\section{Discussion}

From the findings it was observed that AIM strategic planning practices vary between different organizations. The larger the organization is, the more available are the resources and budget to be allocated in strategic planning. Moreover, as a multidiscipline subject, AIM strategic planning involves several business units in the organizations, and all elements are significant in reaching objectives. This statement is opposed to Visser (1998), who views maintenance as the heart of enterprise and hence it should have its own strategic plan. Instead, the findings suggested integration between business units in the organization to reach AIM objectives. This includes integration between, for example, operations, maintenance, production, engineering, supply chain, supports, etc. Consequently, AIM has multiple focus areas, which, according to the respondents, are mostly significant and reliant on one another. These focus areas are analyzed and given prioritization in the planning, due to the limited allocation of resources and budget.

Another factor that will affect the focus areas are the internal and external environments of the organization, such as fluctuating market, competitors, innovation and technology, stakeholders, incidents and accidents, country/region, regulations, etc. This means that these focus areas can vary and are naturally dynamic instead of static. Therefore, to focus on specific areas statically is not a favorable trait in strategic planning, as also suggested by Mintzberg (1994). In contradiction, Tsang (2002) suggested four strategic dimensions in maintenance management. Maintenance is an inseparable part of AIM, thus the notion of static strategic dimension is not in agreement with this study's findings.

Another finding is in line with Grant (2003), who also observed that the AIM planning process is a semi-controlled bottom-up process, where business units are given some degree of freedom in establishing their strategies and performance indicators. Performance management has become a part of the strategic planning process as a monitoring tool and an indicator of the success rate of their plans. Performance management has been acknowledged as a business tool to assess the quality and effectiveness of maintenance, and it would have a similar application in AIM (Parida et al., 2015; Ben-Daya and Duffuaa, 1995).

It was also noted that, despite outsourcing of some AIM activities, none of the organizations was outsourcing their AIM management and planning activities. Since strategic planning is meant to 
secure an organization's competitive advantage, this is in line with (Moreno-Trejo and Markeset, 2012), who suggested that organizations should keep their core competencies in-house.

\section{Concluding remarks}

In the initial part of the paper, it was concluded that organizations were performing strategic planning to secure their competitive advantage for as long as possible; thus forecasts were made to direct the allocation of resources on certain focus areas. From the discussion, it was apparent that the focus areas are dynamic and depends on internal and external factors such as size of the organizations, assets, available resources and budgets, country or region, regulations, etc. Therefore, environmental scanning or other types of assessment for the asset's business environments, is an important step prior to strategic planning formulation.

This paper has also summarized the findings in a study of AIM strategic planning in the petroleum industry. It was observed that the practices of AIM strategic planning vary amongst different organizations, hence mainly depending on the organization's size and the ability to allocate resources and budget. There were different terms of the AIM strategic planning cycle: long-term planning that lasts for the life expectancy of the asset (20-30 years), mid-term planning, which ranges from five to ten years and shorter-term, ranging from one to two years. The intention of the different terms is for the organization to be more adaptive to the fluctuating conditions of the petroleum industry. Performance management also plays an important part in AIM strategic planning, both as business and technical indicators of the strategy's quality and effectiveness. Moreover, the performance review feeds the continuous improvements loop in the strategic planning process and acts as a catalyst for change management.

An updated structure of AIM strategic planning was given in Figure 6, which was the result of discussions with respondents. The new structure suggested a generic practice in AIM business units, bearing in mind that this process is a continuation from the corporate strategic planning process. In the structure, environment scanning or other forms of business assessment for the asset is considered as an important initiation step in the strategy-making process. It was also observed that environment scanning for AIM is a process that is unique due to the AIM business and technical traits. Thus, for future study, it will be advantageous to study the process of AIM environment scanning.

This paper also pointed out the integration of different disciplines in AIM strategic planning; however, the limited study time did not allow further research into the integration mechanism. A further study on the integration and coordination mechanism in AIM would be advantageous, considering that this is one of the main reasons that AIM practices are unsuccessful. 


\section{References}

Al-Turki, U. (2011), "A framework for strategic planning in maintenance", Journal of Quality in Maintenance Engineering, Vol. 17 No. 2, pp. 150-62.

Aven, T. (2008), Risk analysis assessing uncertainties beyond expected values and probabilities, Wiley, Chichester, England; Hoboken, NJ.

Baby, R. (2008), "Integrity Management During Design Stage", paper presented at Abu Dhabi International Petroleum Exhibition and Conference, 3-5 November 2008, Abu Dhabi, UAE.

Bai, Y. and Liyanage, J.P. (2012), "Framework and systematic functional criteria for integrated work processes in complex assets: a case study on integrated planning in offshore oil and gas production industry", Int. J. of Strategic Engineering Asset Management, Vol. 1 No. 1, pp. 49-68.

Ben-Daya, M. and Duffuaa, S.O. (1995), "Maintenance and quality: the missing link", Journal of Quality in Maintenance Engineering, Vol. 1 No. 1, pp. 20-26.

Bharadwaj, U.R., Silberschmidt, V.V. and Wintle, J.B. (2012), "A risk based approach to asset integrity management", Journal of Quality in Maintenance Engineering, Vol. 18 No. 4, pp. 417-31.

Brannen, J. (2005), "Mixing methods: The entry of qualitative and quantitative approaches into the research process", International Journal of Social Research Methodology, Vol. 8 No. 3, pp. 173-84.

Brown, S.L. and Eisenhardt, K.M. (1997), "The art of continuous change: Linking complexity theory and time-paced evolution in relentlessly shifting organizations", Administrative science quarterly, pp. 1-34.

Capon, N., Farley, J.U. and Hulbert, J.M. (1987), Corporate strategic planning, Columbia University Press, New York.

Carr, A.S. and Smeltzer, L.R. (1997), "An empirically based operational definition of strategic purchasing", European Journal of Purchasing \& Supply Management, Vol. 3 No. 4, pp. 199-207.

Casertano, S. (2013), "International oil companies in the post-studio era: Strategic responses of energy majors to the 2003-2008 price boom", Energy Strategy Reviews, Vol. 1 No. 3, pp. 211-17.

Ciaraldi, S.W. (2012), "Why Asset Integrity Implementation Often Fails", Journal of Petroleum Technology, Vol. Volume 64 No. 07, pp. 64-65.

Creswell, J.W. (2003), Research design : qualitative, quantitative, and mixed methods approaches, Sage Publ., Thousand Oaks, California.

El-Akruti, K. and Dwight, R. (2013), "A framework for the engineering asset management system", Journal of Quality in Maintenance Engineering, Vol. 19 No. 4, pp. 398-412.

Grant, R.M. (2003), "Strategic planning in a turbulent environment: Evidence from the oil majors", Strategic Management Journal, No. 24, pp. 491-517.

Grant, R.M. and Cibin, R. (1996), "Strategy, structure and market turbulence: the international oil majors, 1970-1991", Scandinavian Journal of Management, Vol. 12 No. 2, pp. 165-88.

Haines, S. (2000), The systems thinking approach to strategic planning and management, CRC Press, Boca Raton, Florida.

Hax, A.C. and Majluf, N.S. (1984), "The corporate strategic planning process", Interfaces, Vol. 14 No. 1, pp. 47-60. 
Horner, R.M.W., El-Haram, M.A. and Munns, A.K. (1997), "Building maintenance strategy: a new management approachnull", Journal of Quality in Maintenance Engineering, Vol. 3 No. 4, pp. 273-80.

Janele, P.T., Galvin, T.J. and Kisucky, M.J. (1998), "Integrated Asset Management: Work Process and Data Flow Models", paper presented at SPE Asia Pacific Conference on Integrated Modeling for Asset Management, 23-24 March 1998, Kuala Lumpur, Malaysia.

Jansen, B. and Firing, F. (2016), "A Holistic Approach to Safety Barrier Management", paper presented at SPE International Conference and Exhibition on Health, Safety, Security, Environment, and Social Responsibility, 11-13 April, Stavanger, Norway.

Javaherdashti, R., Nwaoha, C. and Tan, H. (2016), Corrosion and Materials in the Oil and Gas Industries, CRC Press.

Killen, C.P., Walker, M. and Hunt, R.A. (2005), "Strategic planning using QFD", International Journal of Quality \& Reliability Management, Vol. 22 No. 1, pp. 17-29.

Kusumawardhani, M., Gundersen, S. and Markeset, T. (2016), "Mapping of research approaches in petroleum industry", Accepted for publication in Journal of Quality in Maintenance Engineering.

Kusumawardhani, M. and Markeset, T. (2015), "Asset Integrity Knowledge Management: A Case Study from the Petroleum Industry", Operations and supply chain management, Vol. 8 No. 3 , pp. $146-53$.

Mankins, M.C. and Steele, R. (2006), "Stop Making Plans; Start Making Decisions", in Harvard Business Review, Harvard Business Publishing, Boston, MA.

Miller, C.C. and Cardinal, L.B. (1994), "Strategic planning and firm performance: a synthesis of more than two decades of research", Academy of Management Journal, Vol. 37 No. 6, pp. 1649-65.

Mintzberg, H. (1994), "The fall and rise of strategic planning", Harvard Business Review, Vol. 72 No. 1, pp. 107-14.

Mitchell, J.V. and Mitchell, B. (2014), "Structural crisis in the oil and gas industry", Energy Policy, Vol. 64, pp. 36-42.

Moreno-Trejo, J. and Markeset, T. (2012), "Mapping Factors Influencing the Selection of Subsea Petroleum Production Systems", in Frick, J. and Laugen, B. (Eds.), Advances in Production Management Systems. Value Networks: Innovation, Technologies, and Management, Springer Berlin Heidelberg, pp. 242-50.

Murthy, D.N.P., Atrens, A. and Eccleston, J.A. (2002), "Strategic maintenance management", Journal of Quality in Maintenance Engineering, Vol. 8 No. 4, pp. 287-305.

Nag, R., Hambrick, D.C. and Chen, M.-J. (2007), "What is strategic management, really? Inductive derivation of a consensus definition of the field", Strategic Management Journal, Vol. 28 No. 9, pp. 935-55.

Parida, A. and Kumar, U. (2009), "Maintenance productivity and performance measurement", in Handbook of maintenance management and engineering, Springer, London, pp. 17-41.

Parida, A., Kumar, U., Galar, D. and Stenström, C. (2015), "Performance measurement and management for maintenance: a literature review", Journal of Quality in Maintenance Engineering, Vol. 21 No. 1, pp. 2-33.

Pinjala, S.K., Pintelon, L. and Vereecke, A. (2006), "An empirical investigation on the relationship between business and maintenance strategies", International Journal of Production Economics, Vol. 104 No. 1, pp. 214-29. 
Quinn, R., Kavanagh, K., Power, J. and Thompson, H. (2007), "Integrated Approach to Subsea Integrity Management: Benefits of Early Field Integrity Management Planning for Chevron's Tahiti Field", paper presented at Offshore Technology Conference, 2007/1/1/, Houston, Texas, U.S.A.

Ratnayake, R.C. (2012), "Modelling of asset integrity management process: a case study for computing operational integrity preference weights", International Journal of Computational Systems Engineering, Vol. 1 No. 1, pp. 3-12.

Ritchie, D.M. (2011), "The Role of Asset Integrity and Life Extension in Major Accident Prevention", paper presented at SPE Offshore Europe Oil and Gas Conference, 6-8 September 2011, Aberdeen, UK.

Smith, C., Wintermute, R., Duran, J., Broussard, K. and Spillman, F. (2002), "Brutus Operational Readiness: Building on Past Projects", paper presented at Offshore Technology Conference, 6-9 May 2002, Houston, Texas.

Sollee, S.S., Luquette, G.P. and Maruta, H. (1995), "A Business Planning Approach that Integrates Asset Management, Strategic Planning and Technology Planning", in Proceedings of Indonesian Petroleum Association 24th Annual Convention, Jakarta, Indonesia.

Standardization, I.O.f. (2014), "ISO 55000:2014", in Asset management - Overview, principles and terminology, International Organization for Standardization, Geneva, Switzerland.

Steiner, G.A. (1979), Strategic planning : what every manager must know, Simon and Schuster, New York.

Sulaiman, S. and Husin, M.T. (2000), "Development of Operations Reference Plan (ORP) for Asset Management", paper presented at SPE Asia Pacific Conference on Integrated Modelling for Asset Management, 2000/1/1/, Yokohama, Japan.

Tsang, A.H.C. (1998), "A strategic approach to managing maintenance performance", Journal of Quality in Maintenance Engineering, Vol. 4 No. 2, pp. 87-94.

Tsang, A.H.C. (2002), "Strategic dimensions of maintenance management", Journal of Quality in Maintenance Engineering, Vol. 8 No. 1, pp. 7-39.

Visser, J. (1998), "Modelling maintenance performance: a practical approach", in IMA conference, Edinburgh, pp. 1-13.

Woodhouse, J. (2003), "Asset Management: A Science Emerging", International Journal of COMADEM, Vol. 6 No. 3, pp. 4-10. 